\title{
Revista Brasileira de Enfermagem REBEn \\ O processo de formação em saúde: o saber resíduos sólidos de serviços de saúde em vivências práticas
}

\author{
The process of education in health: practical knowledge on solid \\ wastes from healthcare services \\ El proceso de formación en salud: el tema residuos solidos de
servicios de salud en vivencias prácticas
}

\section{Luciara Bilhalva Corrêa}

Economista Doméstica. Mestre em Educação Ambiental. Doutoranda em

Educação Ambiental pela Fundação Universidade Federal do Rio Grande/FURG.

Rio Grande, RS. luciarabc@terra.com.br

Valéria Lerch Lunardi

Enfermeira. Doutora em Enfermagem. Docente do Programa de Pós-Graduação em Educação Ambiental e do Departamento de Enfermagem da Fundação Universidade Federal de Rio Grande/FURG, Rio Grande, RS.

Suzana Maria De Conto

Engenheira Química. Doutora em Educação. Docente do Departamento de Engenharia Química do Centro de Ciências Exatas e Tecnologia e do Programa de Pós-Graduação em Turismo. Pesquisadora do Instituto de Saneamento Ambiental da Universidade de Caxias do Sul/UCS, Caxias do Sul, RS.

Trata-se de artigo síntese da dissertação de mestrado do Programa de Pós-Graduação em Educação Ambiental da Fundação Universidade Federal de Rio Grande/FURG.

Submissão: 28/06/2006 Aprovação: 11/12/2006

\section{RESUMO}

O manejo inadequado dos Resíduos Sólidos em Serviços de Saúde (RSSS) representa uma fonte de degradação, oferecendo risco ao ambiente e à saúde. Enfatizar esta questão no processo de formação requer considerar os indivíduos que atuam nestes espaços, na construção de uma consciência ética, em busca da qualidade de vida e sustentabilidade. Para conhecer como o manejo dos RSSS vem sendo construído nos cursos de Enfermagem/Obstetrícia, Odontologia, Medicina e Medicina Veterinária, realizaramse entrevistas com vinte e um sujeitos, coordenadores, docentes e alunos de uma IFES no sul do país, além de uma análise documental. A partir da análise de conteúdo, é possível afirmar que os futuros profissionais vivenciam ações relacionadas à segregação, acondicionamento e coleta em alguns ambientes, porém sem uma compreensão da totalidade deste manejo.

Descritores: Educação em saúde; Saúde ambiental; Enfermagem.

\section{ABSTRACT}

Improper management of solid wastes from healthcare services is a source of contamination and risk to the environment and to the public health. Emphasizing this matter in the process of education requires to take into account the individuals that work in these spaces, for constructing an ethic conscience, aiming at quality of life and sustainability. In order to know the approach on the management of solid wastes from health-care services in the programs of Nursery/Obstetrics, Dentistry, Medicine e Veterinary Medicine, interviews were conducted with twenty one persons, coordinators, teachers and students of an university in Southern Brazil, as well as an analysis of documents. After analyzing the contents, it is possible to state that the future professionals have practices related to segregation, packing and picking in some environments, although they have not a comprehension of the totality of this management. Descriptors: Education in health; Environmental health; Nursing.

\section{RESUMEN}

El manejo inadecuado de los Residuos Solidos en los Servicios de Salud (RSSS) representa una fuente de degradación, ofreciendo riesgo al ambiente y a la salud. Resaltar esta cuestión en el proceso de formación requiere considerar los individuos que actuan en estes espacios, en la construcción de una consciencia ética, buscando calidad de vida y sostenibilidad. Para conocer como el manejo de los RSSS está siendo construido en los cursos de Enfermería/Obstetricia, Odontología, Medicina y Medicina Veterinaria, se conducieron entrevistas con veinte y uno sujetos, coordenadores, docientes y estudiantes de una universidad en el sur de Brasil, así como una análisis documentaria. El análisis del contenido permitió afirmar que los profesionales futuros vivencian acciones relacionadas a la segregación, acondicionamiento y coleta en algunos ambientes, pero sin una comprensión de la totalidad de ese manejo.

Descriptores: Educación en salud; Salud ambiental; Enfermería.

Corrêa LB, Lunardi VL, De Conto SM. O processo de formação em saúde: o saber resíduos sólidos de serviços de saúde em vivências práticas. Rev Bras Enferm 2007 jan-fev; 60(1):21-5.

\section{INTRODUÇÃO}

Os resíduos sólidos de serviços de saúde - RSSS, quando gerenciados inadequadamente, oferecem risco ao ambiente, à vida, por suas características biológicas, químicas e físicas. Portanto, implantar políticas de gerenciamento de resíduos nos diversos estabelecimentos de saúde, torna-se fundamental, tendo em vista a promoção da saúde e a qualidade de vida do ambiente.

Os estabelecimentos de saúde comumente não se constituem em locais biosseguros, sendo identificados resíduos em acondicionamentos inadequados, misturados com outras classes e tipos, 
desperdício de materiais e grande volume de resíduos contaminados. Os problemas relacionados a essa questão são complexos, exigindo não apenas um posicionamento consciente, mas, sobretudo, disponibilidade para colaborar na sua resolução. É possível que existam falhas na formação dos cursos de graduação, de forma de que não privilegiem o estudo dessa temática e também não invistam adequadamente em pesquisas com esse enfoque. As soluções dependem de uma série de decisões tomadas em diferentes níveis do sistema, tais como, profissionais formados de maneira diferente daquela compartimentalizada existente nas universidades ${ }^{(1-4)}$.

Frente à problemática dos resíduos nas instituições de saúde, as soluções apontadas centram-se predominantemente na implantação do seu manejo, sem que o processo como um todo seja abordado. Parece ser predominante a preocupação com a saída do produto dos ambientes geradores, sem considerar todos os fatores que envolvem as etapas do processo de manejo, desde o próprio preparo dos profissionais que muitas vezes se encontram desinstrumentalizados para lidar com os resíduos provenientes das suas atuações.

Assim, considera-se relevante conhecer como o manejo dos RSSS vem sendo construído na formação dos cursos da área da saúde, até mesmo para se ter ciência de todo seu processo, ou seja, ter conhecimento sobre a sua classificação, de como segregar, acondicionar, enfim, todas as demais etapas. Julga-se que somente o conhecimento não seja suficiente, implicando também o exercício de cidadania, quanto aos deveres em relação a essa problemática. Ainda, se os profissionais colaborarem ou não com o manejo, sua transgressão não implica necessariamente uma punição, pois comumente não é identificado quem o fez ou as possiveis conseqüências destas ações e/ou omissões, reforçando a importância da necessidade da responsabilidade frente às questões éticas envolvidas.

Neste texto, especificamente, buscamos mostrar como o saber RSSS vem sendo vivenciado na prática no processo de formação dos cursos da área da saúde.

\section{METODOLOGIA}

Trata-se de uma pesquisa com abordagem qualitativa(5) realizada em uma Instituição Pública de Ensino Superior da região sul do país, enfocando quatro cursos de graduação da área da saúde, Enfermagem e Obstetrícia (EO); Odontologia (O); Medicina (M) e Medicina Veterinária (MV). Os dados foram coletados através de entrevistas semi-estruturadas com quatorze alunos (a) de final de curso; três docentes (d) de disciplinas relacionadas ao saber em questão e quatro coordenadores (c) de colegiados de curso, e também de uma análise documental dos projetos políticopedagógicos e planos de ensino. Nas entrevistas, foram abordadas, dentre outros, a abordagem dos RSSS; conhecimentos e vivências; fragilidades e/ou facilidades encontradas neste processo. Os dados foram analisados a partir da análise de conteúdo proposta por Moraes(6).

O projeto de pesquisa foi aprovado pela Comissão de Ética em Pesquisa da Santa Casa de Misericórdia. Ao iniciar o processo de coleta de dados, foi realizada a obtenção do consentimento livre esclarecido dos participantes.

\section{RESULTADOS E DISCUSSÃO}

As vivências práticas acerca do saber RSSS no processo de formação, em sua grande maioria, acontecem em estabelecimentos de saúde, de um modo mais aproximado à realidade profissional e a partir da geração de resíduos resultante dos procedimentos realizados. Assim, os dados foram organizados privilegiando as etapas do processo do manejo dos RSSS: geração, minimização, segregação, reciclagem, acondicionamento, armazenamento, coleta, tratamento e disposição final. Foi identificado nos depoimentos que os sujeitos têm conhecimento de algumas das etapas do manejo, de sua relevância e implicações, porém de modo fragmentado e isolado. Entretanto, expressam a necessidade e o desejo de articular 0 processo da abordagem dos RSSS como um todo. Assim, possivelmente, a universidade necessite promover um pensamento capaz de relacionar, de interligar, no processo de ensino, buscando a relação de inseparabilidade e inter-retroações entre todo o fenômeno e seu contexto( ${ }^{(7)}$

Os estudantes dos cursos $E O, O$ e $M$, referiram vivência com a geração de resíduos em aulas práticas já no início da formação:

muita coisa a gente gera aqui na faculdade, mas a gente precisava ficar sabendo de mais coisas, além dessa separação (a3/0).

As ações, no âmbito das clínicas, parecem centradas apenas na separação dos resíduos, confirmando a visão fragmentada deste saber. É possivel que, se desde então, essa questão fosse problematizada, mostrando a relevância das diferentes etapas do seu manejo para a sustentabilidade do ambiente e a saúde das pessoas, articulando com os demais espaços de vivências práticas, uma melhor compreensão e instrumentalização para o seu enfrentamento poderia ser alcançada nas demais etapas da formação como também na sua vida profissional.

Um estudo ${ }^{(8)}$ realizado com 58 odontólogos, referente aos resíduos sólidos, demonstra problemas na capacitação desses profissionais para lidar de forma apropriada com os resíduos, expressos pelas dificuldades em segregar adequadamente resíduos infectantes, especiais e comuns, decorrendo uma produção excessiva do grupo dos infectantes e especiais, bem como um destino final inadequado. Esse proceder gera "mistura" de diferentes categorias de resíduos, ocasionando um duplo problema, pois resíduos infectantes e especiais são tratados como comuns, enquanto que resíduos comuns são tratados como infectantes, não recebendo tratamento adequado, representando um risco real à proteção à saúde individual $e$ coletiva, com gastos por vezes desnecessários de energia e de recursos. A legislação é pouco considerada nesse âmbito profissional; falta clareza quanto aos riscos potenciais dos resíduos odontológicos, bem como é inadequada a utilização dos Equipamentos de Proteção Individual (EPIs) para o seu manejo.

Isso nos remete ao projeto político-pedagógico do curso que, dentre outras habilidades, prevê a formação de um profissional capaz de trabalhar em equipes interdisciplinares, de atuar como agente de promoção de saúde, e de planejar e administrar serviços de saúde comunitária.

Um outro depoimento demonstra que, em geral, os profissionais da Medicina não se envolvem com a geração de resíduos, o que pode estar associado ao modelo ainda predominantemente adotado na formação e no exercício profissional, ou seja, com ênfase na doença, no seu tratamento e na recuperação e não na sua prevenção e na promoção da saúde:

acho que dos cursos superiores da área da saúde, a enfermagem é que possa ver a questão dos resíduos (...) é função da enfermagem mesmo. No hospital, como existe um serviço forte de enfermagem, os resíduos fica mais atrelada a elas, o médico não se envolve muito... (c/M);

o que de certo modo é confirmado pelo coordenador da EO:

(...) a questão dos resíduos hospitalar, quem mais se preocupa com isso, é a enfermagem, por causa da infecção hospitalar...

Um maior envolvimento da enfermagem no manejo dos RSSS, por assumirem um papel de administradores da instituição, pode favorecer a situação de que outros profissionais se reconheçam como desobrigados de assumirem essa função. Entretanto, o envolvimento e a responsabilidade para com os RSSS, desde a sua geração até a disposição final, faz parte do exercício de cidadania de todos sujeitos ali atuantes.

Os alunos dos cursos EO, $O$ e $M V$, referiram que, ao iniciarem atividades práticas, foram orientados em relação à segregação e ao acondicionamento dos RSSS. No entanto, questionam sua falta de 
compreensão da totalidade, demonstrando que até entenderam o processo, mas se vêem, como futuros profissionais, inseguros de como, no mundo da prática real, necessitariam e deveriam agir. É pertinente destacar que 0 conhecimento das etapas de segregação e de acondicionamento são de extrema relevância para a continuidade de um adequado processo de manejo, o que implica a colaboração e o comprometimento de todos os envolvidos, já que a sua segregação traz como benefício: a) minimizar a geração de resíduos e os custos do seu tratamento e disposição final; b) permitir seu manuseio, tratamento e a disposição final adequado conforme sua categoria; c) evitar a contaminação de uma grande massa de resíduos por uma pequena quantidade perigosa; d) separar os resíduos perfurantes e cortantes, evitando, assim, acidentes no seu manejo; e e) comercializar os resíduos recicláveis ${ }^{(9)}$.

Os estudantes de $E O$ referiram que apesar de terem sido orientados pelo docente, em aula prática, acerca da separação dos resíduos gerados pelas atividades, não percebiam uma segregação rigorosa dos resíduos no âmbito hospitalar:

às vezes a enfermeira ta separando tudo (...) aí chega alguém da medicina, ou um técnico de enfermagem, e colocam luvas cheia de sangue, dentro das outras lixeiras que tem material que ta separado (...) dá uma agonia, mas acontece (a3/EO).

Nessa fala, o sujeito parece fazer alusão à etapa da reciclagem, quando se refere a dois ou mais dispositivos para acondicionar a segregação dos resíduos; no entanto, é possível que um desses dispositivos pudesse vir a ser utilizado para acondicionar resíduos recicláveis, tais como, plásticos, papel/papelão, vidros, metal. Assim, esses materiais, uma vez perdida sua utilidade, são descartados como resíduos; no entanto, podem ser passíveis de reutilização, passando novamente pelo processo de industrialização, na forma de matéria-prima secundária, com recuperação de matéria e energia, contribuindo para a preservação dos recursos naturais. A etapa de reciclagem, entretanto, ainda é arriscada nas instituições de saúde, por não se conseguir uma segregação eficiente na fonte geradora; assim, corre-se o risco de contaminação devido à mistura desses materiais com resíduos químicos ou infectantes ${ }^{(10)}$.

Um outro aspecto apontado refere-se ao descomprometimento dos próprios formadores em relação à segregação dos resíduos:

\section{(...) a gente vê professores procedendo errado também, a gente precisa saber mais detalhes sobre o lixo gerado aqui nas clínicas... (a1/0).}

Em se tratando do acondicionamento, os acadêmicos da EO perceberam, em um posto de saúde gerenciado pela própria instituição de ensino, que:

\section{(...) eles colocavam numas caixas de papelão, não tinha lixeira,botavam numa caixa de papelão com um saco... (a2/EO).}

Em outras situações, não eram disponibilizados sacos plásticos, desse modo, as próprias lixeiras ficavam contaminadas com resíduos com secreções e geralmente não acontecia sua limpeza. Uma estratégia adotada pelos alunos juntamente com uma professora de disciplina prática da $E O$ foi a construção de um projeto, contactando a administração da Instituição, solicitando equipamentos para a implantação da segregação dos materiais (lixeiras, sacos para acondicionamento) no posto de saúde. No entanto, não perceberam a continuidade da implantação desse projeto:

(...) não sei se foi feito, se eles levaram as lixeiras, se tá sendo levado a sério a separação dos resíduos. Nós saímos, então, entra outro grupo, outro semestre começa, a gente não sabe se vai dar andamento desse projeto no posto (...) Era importante que a professora conseguisse que isso fosse adiante, mas não sei, não sei... (a1/EO).

Os próprios alunos consideram que a continuidade do desenvolvimento do projeto seria relevante para a formação dos futuros profissionais no curso, tanto pela possibilidade de implantar o preconizado no manejo dos RSSS, como pela transformação de uma realidade e também pelo caráter pedagógico de aproximação da teoria à prática. Daí, a importância e necessidade de um planejamento anterior à execução das ações, que as atividades sejam organizadas e articuladas entre os semestres, demonstrando a responsabilidade e comprometimento com os investimentos voltados à solução de problemas sociais. Essa situação vivenciada, mais uma vez, aponta para a fragmentação do ensino: não somos preparados para pensar as ações, compreendendo que estão relacionadas e interligadas. O processo de formação mostra-se recortado em disciplinas e em semestres:as vivências práticas não parecem ter relação com conteúdos teóricos.

Também cabe destacar que a iniciativa de implantação de um sistema de segregação no posto de saúde não assegura seu funcionamento. Fazse necessário considerar os profissionais que atuam nesse âmbito, seus desejos, sua compreensão da problemática dos RSSS e do seu possivel enfrentamento. É possível que esses profissionais não possuam uma visão crítica da relação dos resíduos com suas ações, da contaminação do ambiente de trabalho, dos riscos de acidente, da poluição ambiental, mostrando-se indiferentes à presença ou não de dispositivos adequados para segregar e acondicionar os resíduos.

Nos serviços de saúde, nem sempre se apresentam condições ideais para um adequado manejo dos resíduos ou, diferentemente, pode ser que, apesar da existência de excelentes condições, o manejo adequado não aconteça. Nessas duas situações, o aparente descomprometimento não implica, comumente para as pessoas envolvidas, uma penalização pelas suas ações. No entanto, a questão dos RSSS extrapola o fazer individual, implica uma consciência ética, de responsabilidade com o meio, de cidadania, de respeito aos outros ${ }^{(11)}$.

Houve referência às dificuldades no armazenamento dos resíduos:

(...) o lixo é colocado lá na frente, é fechado e gradeado com um cadeado, mas fica à mostra, quem passa na calçada vê esse lixo, às vezes tem luva pendurada pra fora. Nos fins de semana, os catadores arrombam para pegar os plásticos, e fica tudo atirado no chão... (a1/0).

Este sujeito, também, faz referência à reciclabilidade nos locais que prestam serviços à saúde. No entanto, se não existe uma segregação eficiente, é possível que os materiais estejam contaminados por estarem misturados com outros tipos de resíduos:

(...) esse lixo todo do posto é colocado na rua, na calçada, que daí o caminhão recolhe (...) não tem nenhum local lá dentro para esse lixo... (a2/EO).

Os depoimentos expressam que, freqüentemente, nas instituições de saúde, não são previstos espaços para a estocagem da geração de resíduos resultantes das atividades da saúde, o que já havia sido constado em estudo sobre o manejo dos resíduos sólidos urbanos no âmbito das residências ${ }^{(12)}$, permitindo considerar que os resíduos não têm sido priorizados nos projetos de engenharia. Cabe destacar que os RSSS não podem ser uma preocupação isolada de seus profissionais ou de técnicos de engenharia ou arquitetura, requerendo, cada vez mais, ações integradas dos diferentes atores responsáveis pelo manejo de resíduos sólidos de serviços de saúde: técnicos, políticos, administradores, cientistas e outros profissionais.

De acordo com a legislação(13), cada unidade geradora necessita de uma sala de resíduo apropriada para o armazenamento interno, enquanto que o armazenamento externo requer um local exclusivo para a guarda 
temporária dos RSSS, até o momento de sua coleta.

Retomando novamente os projetos político-pedagógicos dos cursos, é possivel perceber uma proposta de formação pautada nos princípios da ética, respeito, responsabilidade social e cidadania, em uma perspectiva de integralidade, de modo que o profissional, como um ser reflexivo, participativo e crítico, seja capaz de trabalhar coletivamente, atuando na melhoria da qualidade de vida, defendendo e preservando a vida, estabelecendo relações com o contexto social.

Apesar de os acadêmicos apontarem acidentes atrelados à coleta dos resíduos, principalmente associados a perfurantes e cortantes, seja pelo seu manejo inadequado, seja pelo não uso de EPIs, foi percebido que, em geral, essas situações não são comentadas e tampouco há sua problematização:

(...) na hora que a gente fica sabendo que alguém se pisou, (...) é porque possivelmente alguém fez errado, a gente fica meio pensando, da nossa responsabilidade com isso, mas depois, acaba esquecendo (...) $(\mathrm{a} 3 / \mathrm{M})$.

Esse agir de forma descompromissada com a realidade remete-nos à necessidade de responsabilidade do sujeito consigo mesmo e com os outros, aos valores de solidariedade e responsabilidade com a vida e 0 ambiente, em que cada um assume sua parcela. Os valores necessitam ser vividos no fazer cotidiano de cada um. Da mesma forma, a ética precisa estar na essência do ato de educar como parte da prática do educador e do ato educativo(14).

Quanto ao tratamento dos resíduos, no Curso MV, foi apontado que:

(...) aqui, nós temos um forno, a gente sabe que ele não está nos padrões certos, mas o que temos é isso por enquanto. Todos os resíduos contaminados do hospital veterinário são queimados lá, agora o forno está quebrado; mas seguidamente ele apresenta falhas. Então nós não estamos conseguindo tratar os resíduos, eles estão acumulados lá fora, longe daqui do hospital... (d1/MV).

É possivel depreender que a forma de tratamento adotada para os resíduos gerados é a incineração; no entanto, o equipamento aparentemente apresenta problemas e, como alternativa, o sujeito aponta para a disposição final desses resíduos num outro local, possivelmente de forma inadequada. Também, como destino final, outro sujeito faz referência ao descarte dos reveladores, gerados nas aulas práticas de radiologia. Os reveladores, como resíduos químicos e por conterem metais pesados, como a parta, são classificados como resíduos perigosos. Portanto, seu descarte no ambiente apresenta riscos à saúde pública e ao meio, devendo ser acondicionado e encaminhado ao fabricante para posterior recuperação da prata antes de seu descarte. Essa recomendação implica a etapa de minimização, ou seja, são ações de recuperação e regeneração de RSSS ${ }^{(10)}$.

Cabe destacar que inexiste uma política ambiental na instituição em estudo, voltada para o gerenciamento de resíduos resultantes das diferentes atividades, possibilitando que ações para um adequado manejo, muitas vezes ocorram de forma lenta, desorganizada e desarticulada, e, até, ineficaz. No que se refere aos RSSS, gerados na instituição, é possivel afirmar que apenas são realizadas ações como a tentativa de segregação, acondicionamento e coleta diferenciada em alguns locais.

A discussão referente ao gerenciamento dos resíduos nas IES brasileiras é recente. Em algumas, já há profissionais que demonstram uma maior preocupação com essa questão, organizando-se, enquanto que, em outras, ainda não acontece. Assim, os coordenadores dos quatro cursos em estudo referiram que os currículos estão sofrendo uma reforma, sendo estimulada uma sólida formação geral, necessária para que o futuro graduado possa vir a superar os desafios de renovadas condições de exercício profissional e de produção do conhecimento, sendo provável que a abordagem dos RSSS possa ocupar um espaço nesse processo.

\section{CONSIDERAÇÕES FINAIS}

O manejo inadequado dos RSSS tem causado sérias implicações para o ambiente, fazendo-se necessário que os sujeitos participantes desses espaços tenham uma visão mais abrangente para o enfrentamento dessa problemática. Uma das missões da educação e da universidade é reformar o ensino para reformar o pensamento, para formar cidadãos capazes de enfrentar os problemas do seu tempo, capazes de ligar conhecimentos desarticulados, capazes de prolongar-se numa ética da dependência e solidariedade entre seres humanos.

Educar é impregnar de sentidos as práticas e os atos. É a partir da vida cotidiana, das necessidades e interesses pessoais que as exigências de uma sociedade planetária precisam ser pedagogicamente trabalhadas. É a partir do dia-a-dia que se constrói a cultura da sustentabilidade, de valorização da vida. No cotidiano, se expressam as formas de viver/ conviver e é aí que necessitamos criar novas formas de ser e de estar no mundo, a partir de reflexões significativas sobre as realizações do aprendiz. Ao refletir sobre o seu fazer diário, o ser estará, simultaneamente, autotransformando-se e auto-modificando-se.

Fica evidente a necessidade de olhar para a abordagem dos RSSS nos cursos de graduação da área da saúde. É necessário que este saber não seja apenas uma informação de como fazer, mas que o espaço de formação propicie reflexão, problematização, crítica, articulação, comprometimento com a construção de sujeitos que incorporem posturas éticas, de solidariedade, de consciência cidadã, de compromisso social, atuando de forma responsável para com o meio.

É fundamental que os docentes se comprometam, incorporando atitudes de desafio em suas práticas pedagógicas, na busca de novas compreensões, rompendo com ações fragmentadas, acomodadas e, partindo para as incertezas, para as instabilidades, para o imprevisto, reconheçam o processo educativo como um vir a ser, em movimento, em fluxo, em permanente processo de mudança.

\section{REFERÊNCIAS}

1. Schneider VE, Caldart V, Gastaldello MET. A caracterização de resíduos de serviços de saúde como ferramenta para a monitorização de sistemas de gestão destes resíduos em estabelecimentos hospitalareS. In: Anais do $2^{\circ}$ Congresso Interamericano de Engenharia Sanitária e Ambiental; 2000; Porto Alegre (RS), Brasil. Porto Alegre (RS): ABES; 2000.

2. Stédile NLR. Sistematização de fontes geradoras de resíduos sólidos de serviços de saúde como subsídio para proposição de programas de gerenciamento em estabelecimentos de assistência primária e secundária. In: Anais do $9^{\circ}$ Simpósio Luso-Brasileiro de Engenharia Sanitária e Ambiental; 2000; Porto Seguro (BA), Brasil. Porto Seguro (BA): ABES; 2000. p. 1477-86
3. Coelho H. Gestão de rejeitos em saúde: como descartar, aproveitar e gerenciar. J Assoc Nac Biossegurança 2003;3(10).

4. Garcia LP, Zanetti-Ramos BG. Gerenciamento dos resíduos de serviços de saúde: uma questão de biossegurança. Cad Saúde Pública 2004;20(3):744-52.

5. Minayo MCS. $O$ desafio do conhecimento: pesquisa qualitativa em saúde. 6a ed. São Paulo (SP): Hucitec-Abrasco; 1999.

6. Moraes R. Uma tempestade de luz: a compreensão possibilitada pela análise textual discursiva. Ciência \& Educação 2003, 9(2):191-211.

7. Morin E. Complexidade e transdisciplinaridade: a reforma da universidade e do ensino fundamental. Natal (RN): EDUFRN, 1999. 
O processo de formação em saúde: o saber resíduos sólidos de serviços de saúde em vivências práticas

8. Schneider VE. Modelos de gestão de resíduos sólidos de serviços odontológicos (RSSO) por meio do índice de geração percapita. In: Anais do $28^{\circ}$ Congreso Interamericano de Ingeniería Sanitaria y Ambiental; 2002, Cancun (México). Cancun (MEX): ABES; 2002.

9. Takayanagui AMM. Trabalhadores de saúde e meio ambiente: ação educativa do enfermeiro na conscientização para o gerenciamento de resíduos sólidos (tese). Ribeirão Preto (SP): Escola de Enfermagem de Ribeirão Preto, Universidade de São Paulo; 1993.

10. Schneider VE. Manual de gerenciamento de resíduos sólidos em serviços de saúde. 2a ed. Caxias do Sul (RS): Educs; 2004.
11. Ferreira JA. Resíduos sólidos e lixo hospitalar: uma discussão ética. Cad Saúde Pública 1995;11(2):314-20.

12. Mandelli SMDC. Variáveis que interferem no comportamento da população urbana no manejo de resíduos sólidos domésticos no âmbito das residências (tese). São Carlos (SP): Universidade Federal de São Carlos; 1997.

13. Associação Brasileira de Normas Técnicas. NBR 12.809: manuseio de resíduos de serviços de saúde - procedimento. Rio de Janeiro (RJ): ABNT; 1993.

14. Moraes MC. Pensamento eco-sistêmico: educação, aprendizagem e cidadania no século XXI. Petrópolis (RJ): Vozes; 2004. 